\title{
Plasma Osmolality Dipsogenic Thresholds and c-fos Expression in the Near-Term Ovine Fetus
}

\author{
ZHICE XU, MARK J.M. NIJLAND, AND MICHAEL G. ROSS \\ Perinatal Research Laboratory, Department of Obstetrics and Gynecology, Harbor UCLA-Medical Center, \\ Torrance, California 90502, U.S.A. [Z.X., M.G.R.]; and Laboratory for Pregnancy and Newborn \\ Research, College of Veterinary Medicine, Cornell University, Ithaca, New York 14853, U.S.A. [M.J.M.N.]
}

\begin{abstract}
In ovine and human pregnancy, fetal swallowing contributes importantly to amniotic fluid homeostasis. Fetal dipsogenic responsiveness to short-term plasma hyperosmolality develops in late gestation, although fetal swallowing is not stimulated in response to long-term plasma osmolality increases (2 to $3 \%$ ), which typically stimulate adult drinking behavior. To explore the near-term fetal plasma osmolality threshold for swallowing stimulation, we examined the effects of i.v. hypertonic saline-induced subacute increases in plasma hypertonicity on fetal swallowing behavior. Central sites of activation were examined by c-fos expression in putative dipsogenic nuclei. The results demonstrate that subacute 2 to $3 \%$ plasma osmolality increases do not stimulate near-term ovine fetal swallowing. However, fetal swallowing activity significantly increased (3 times) after plasma osmolality increased $>6 \%$ above basal values. Consistent with a specific dipsogenic response, i.v. hypertonic saline induced c-fos expression in the anterior third ventricle region, a putative dipsogenic center, as well as in the fetal hindbrain. The stimulation of fetal swallowing under conditions of higher osmotic stimulation and the correlation with forebrain c-fos expression indicates that near-term fetal osmoregulation mechanisms are functional, although not completely mature. Reduced fetal dipsogenic re-
\end{abstract}

\section{ABSTRACT}

sponsiveness may result from altered osmoreceptor sensitivity, downstream neuronal or synaptic immaturity, or potentially inhibitory actions of stimulated hindbrain nuclei. (Pediatr Res 49: 678-685, 2001)
AP, area postrema
ECoG, electrocortical activity
EMG, electromyograph
FOS-ir, FOS immunoreactivity
Hct, hematocrit
HV, high voltage
$\mathbf{L V}$, low voltage
LPBN, lateral parabrachial nuclei
MnPO, median preoptic nuclei
NTS, nuclei of solitary tract
OVLT, organum vasculosum of the lamina terminalis
PVN, paraventricular nuclei
$\mathbf{P o}_{2}$, arterial oxygen tension
$\mathrm{PCO}_{2}$, arterial carbon dioxide tension
SFO, subfornical organ
SON, supraoptic nuclei

Abbreviations:
Intravascular osmolality and body fluid homeostasis are maintained primarily by coordination of thirst-mediated drinking behavior and neuroendocrine-mediated renal fluid regulatory mechanisms. During in utero development, fetal swallowing contributes importantly to amniotic fluid volume homeostasis. Previous studies in this laboratory have demonstrated that near-term ovine fetal swallowing is stimulated by intravenous, intracarotid, and intracerebroventricular hyperosmolality (1-4), consistent with the activation of central osmoreceptors in regions responsive to both vascular and cerebrospinal fluid tonicity. Despite intact fetal osmotic-dipsogenic responsiveness, fetal swallowing is not stimulated in response

Received April 26, 2000; accepted November 23, 2000.

Correspondence and reprint requests: Zhice Xu, Ph.D., Perinatal Research Laboratory, Harbor/UCLA Medical Center, 1124 West Carson Street, Torrance, CA 90502, U.S.A.; e-mail: z_xu@prl.humc.edu

Supported by grant No.DK43311 (M.G.R.) from the National Institutes of Health. to plasma osmolality increases (2 to $3 \%$ ), which typically stimulate adult drinking behavior. For example, despite continually elevated plasma osmolality $(10-14 \mathrm{mosmol} / \mathrm{kg})$ in response to short-term i.v. hypertonic saline injection, fetal swallowing activity is only stimulated for a maximum of $5 \mathrm{~min}$ (1). Furthermore, long-term increases in plasma osmolality of $10 \mathrm{mosmol} / \mathrm{kg}$ do not alter fetal swallowed volume (5). These responses suggest either a reduced population of fetal osmoreceptor cells, reduced sensitivity of osmoreceptors, or altered secondary neural mechanisms, in comparison to the adult.

c-fos expression has been well described as a marker of neuronal activation in both adult and fetal brain nuclei (6). McDonald et al. (7) recently showed that FOS-ir was evident in the SFO, OVLT, and MnPO, as well as in the PVN and SON of the near-term fetal forebrain in response to maternal hypertonicity. These results are comparable to physiological and $c$-fos responses observed in adult animals (8-11). In response 
to fetal intraperitoneal hypertonic saline, fetal FOS-ir responses to $10 \mathrm{mosmol} / \mathrm{kg}$ increases in plasma osmolality suggest that the elevated fetal plasma osmolality threshold (for swallowing stimulation) is not caused by reduced osmoreceptor populations or sensitivity (12). However, stress and pain (potentially in response to intraperitoneal hypertonicity) may induce c-fos expression in similar areas as that induced by osmotic stimuli (e.g. PVN and SON) $(13,14)$.

In the present study, we sought to examine the fetal plasma osmolality threshold for the stimulation of swallowing activity. To confirm a principal dipsogenic mechanism in the absence of an induced stress response, central sites of activation were examined by c-fos expression in forebrain dipsogenic nuclei and select hindbrain regions. The results provide important information for understanding the early development of the osmoregulatory mechanisms for body fluid homeostasis.

\section{METHODS}

Eleven time-dated pregnant ewes with singleton fetuses (130 $\pm 2 \mathrm{~d}$ gestation on the study day) were used. Animals were housed in individual study cage and in a light-controlled room (12 h light/ $12 \mathrm{~h}$ dark) with food and water provided al libitum. The study was approved by our institution.

Surgical preparation. Anesthesia was induced with ketamine hydrochloride $(20 \mathrm{mg} / \mathrm{kg}$, intramuscular), and general anesthesia was maintained with 1 to $2 \%$ isoflurane and $1 \mathrm{~L} / \mathrm{min}$ oxygen. Surgical placement of bipolar electromyography electrodes (thyrohyoid muscle, upper and lower nuchal esophagus) for determination of swallowing activity was performed as previously reported $(15,16)$. Electrodes were also implanted on the parietal dura through two burr holes for the determination of fetal ECoG. Polyethylene catheters were placed in the femoral artery and vein and threaded to the inferior vena cava and abdominal aorta, respectively, for both fetus and ewe. An intrauterine catheter (Corometrics Medical System, Wallingford, CT, U.S.A.) was inserted for measuring amniotic fluid pressure. All catheters and electrodes were externalized to the maternal flank and placed in a cloth pouch. Animals recovered for $5 \mathrm{~d}$ after surgery, which included catheter maintenance and antibiotic administration.

Behavioral and physiological experiments. Animals were studied only if the fetal arterial $\mathrm{pH}>7.3$. Studies began with a baseline period ( -120 to $0 \mathrm{~min}$ ) followed by the study period ( 0 to $160 \mathrm{~min}$ ). There were two groups of animals (control, $n$ $=5$; experimental, $n=6$ ). To minimize transplacental fluid alterations, the experimental study sought to increase both fetal and maternal plasma osmolality in parallel. Beginning at time 0 , hypertonic saline $(0.85 \mathrm{M} \mathrm{NaCl})$ was infused i.v. into the maternal ewe and fetus ( 2.5 and $0.5 \mathrm{~mL} / \mathrm{min}$, respectively) for $60 \mathrm{~min}$, after which the infusate was changed to $4 \mathrm{M} \mathrm{NaCl}$ for an additional $20 \mathrm{~min}$ (to achieve a further increase in plasma osmolality). For the control animals, isotonic $(0.15 \mathrm{M}) \mathrm{NaCl}$ was infused i.v. into the maternal ewe and fetus (2.5 and 0.5 $\mathrm{mL} / \mathrm{min}$, respectively, for $60 \mathrm{~min}$ ). After hypertonic and isotonic infusions, animals were continually observed for another 80 min.
Throughout the study maternal and fetal blood pressures and heart rates, amniotic fluid pressure, fetal swallowing activity, and ECoG were measured continuously. Maternal and fetal blood samples were collected at -60 and -30 min of the baseline period and at $15,30,60$, and $100 \mathrm{~min}$ after initiation of the i.v. infusions. Fetal and maternal blood pressures and amniotic fluid pressure were measured by means of a Beckman R612 (Beckman Instruments, Fullerton, CA, U.S.A.) physiological recorder with Statham (Garret, CA, U.S.A.) P23 transducers. Fetal blood pressure was corrected for amniotic cavity pressure.

Maternal and fetal blood samples were collected into iced tubes containing lithium heparin. Blood aliquots were assessed for $\mathrm{Hct}, \mathrm{Hb}, \mathrm{pH}, \mathrm{PO}_{2}$, and $\mathrm{P}_{\mathrm{CO}_{2}}$; remaining blood was centrifuged, and plasma osmolality and sodium, chloride, and potassium concentrations were measured, as was AVP by immunoradioassay (AVP results reported separately). Fetal blood samples were replaced with an equivalent volume of heparinized maternal blood withdrawn before the study. Blood $\mathrm{Po}_{2}$, $\mathrm{PCO}_{2}$, and $\mathrm{pH}$ were measured at $39^{\circ} \mathrm{C}$ with a Radiometer $\mathrm{BM} 33$ MK2-PHM 72 MKS acid-base analyzer system (Radiometer, Copenhagen, Denmark). Plasma osmolality was measured by freezing point depression on an Advanced Digimatic osmometer (model 3MO, Advanced Instruments, Needham Heights, MA, U.S.A.). Plasma sodium, potassium, and chloride concentrations were determined by a Nova 5 electrolyte analyzer (Nova Biomedical, Waltham, MA, U.S.A.).

Immunohistology experiments. At the end of the study, fetuses were perfused under ketamine anesthesia $(20 \mathrm{mg} / \mathrm{kg}$, intramuscular). All animals were perfused via the carotid artery with $0.01 \mathrm{M}$ PBS followed by $4 \%$ paraformaldehyde in $0.1 \mathrm{M}$ PB. Postfixation was performed in paraformaldehyde solution for $12-24 \mathrm{~h}$, after which brains were placed in $20 \%$ sucrose in $0.01 \mathrm{M}$ PBS overnight. Thirty-micrometer coronal sections of fetal brain were cut through the forebrain and hindbrain on a cryostat. Every other section of the OVLT, MnPO, and SFO and every third section of other parts of the forebrain were used for FOS-ir staining using avidin-biotin-peroxidase technique. The primary antibody (Santa Cruz Biotech, Santa Cruz, CA, U.S.A.) was raised from rabbits against FOS protein in cells. The tissue sections were incubated for $1 \mathrm{~h}$ at room temperature on a gentle shaker, then overnight at $4^{\circ} \mathrm{C}$ in the primary antibody (FOS antibody with $0.3 \%$ Triton X-100). The sections were further incubated in goat anti-rabbit serum (1:500) and then processed using the Vectastain ABC kit (Vector Labs, "Elite" ABC reagent, Burlingame, CA, U.S.A.). The sections were treated with $1 \mathrm{mg} / \mathrm{mL}$ diaminobenzidine tetrahydrochloride (Sigma Chemical Co., St. Louis, MO, U.S.A.). All sections were placed on gelatinized slides, dehydrated in alcohol, and then coverslipped.

Analysis. EMG signals were processed as previously described (17). An EMG-propagated swallow, representing a coordinated laryngeal-esophageal contraction, was defined by a time sequence of integrated EMG signals from the thyrohyoid muscle to the upper and lower nuchal esophagus (17). ECoG pattens were discriminated into HV and LV periods. Because fetal swallowing activity occurs predominantly during periods of LV ECoG activity (18), change in the relative 
duration of LV periods may influence the swallowing rate. Thus, swallowing data are presented as swallows per minute of LV ECoG activity. Fetal blood pressure was adjusted for amniotic fluid pressure.

The number of FOS-ir-positive cells in fetal brain sections was evaluated in a qualitative manner by microscopy analysis. In each control and experimental case, positive FOS-ir counting within the specified brain regions was the same as that reported previously (19). The regions counted were the OVLT, $\mathrm{MnPO}$, and SFO in the forebrain (results for SON and PVN reported separately) and the AP, NTS, and LPBN in the hindbrain.

Repeated measures ANOVA was used to determine differences as a function of time and effects of treatments. Comparisons before and after treatments were determined with oneway ANOVA followed by Scheffé's test or $t$ test. All data are expressed as mean $\pm \mathrm{SEM}$.

\section{RESULTS}

Plasma osmolality, electrolytes, basal arterial values, and cardiovascular responses. Eleven animals successfully completed the study; in one animal, the arterial catheter for measuring blood pressure was nonfunctional. For the control group, i.v. $0.15 \mathrm{M} \mathrm{NaCl}$ had no effect on either maternal or fetal plasma osmolality, $\mathrm{Na}^{+}, \mathrm{K}^{+}$, and $\mathrm{Cl}^{-}$concentrations, or arterial blood $\mathrm{pH}$, blood gases, $\mathrm{Hb}$, and Hct (Tables 1 and 2). However, the analysis demonstrated a significant difference in the plasma osmolality and $\mathrm{Na}^{+}$responses between the control and treated animals $\left(F_{8,1}=49.5\right.$ and 8.25, $p<0.01$ and 0.05 , respectively). In the experimental animals, fetal plasma osmolality and sodium concentration increased slightly, although not significantly, at $30 \mathrm{~min}$ of the $0.85 \mathrm{M} \mathrm{NaCl}$ infusion with a significant increase demonstrated at $60 \min (311 \pm 2$ to 318 $\pm 6 \mathrm{mosmol} / \mathrm{kg}, 147 \pm 1$ to $151 \pm 3 \mathrm{mEq} / \mathrm{L}$, respectively) and a further increase in response to the 20-min infusion of $4 \mathrm{M}$ $\mathrm{NaCl}\left(334 \pm 3 \mathrm{mosmol} / \mathrm{kg}, 163 \pm 1 \mathrm{mEq} / \mathrm{L}\right.$, respectively; $F_{19,4}$ $=15.19, p<0.01$; Table 3). Consistent with the study objectives, maternal plasma osmolality and $\mathrm{Na}^{+}$concentration also significantly increased at 60 and $100 \mathrm{~min}$ of the study $\left(F_{19,4}=8.3\right.$ and 23.7, $p<0.01$; Table 4). Maternal and fetal blood $\mathrm{pH}, \mathrm{Po}_{2}, \mathrm{PCO}_{2}$, and Hct were not changed in response to the hypertonic saline infusions (Tables 3 and 4). Fetal arterial blood pressure or heart rate was not significantly changed in response to isotonic and hypertonic saline infusions (Table 5). Maternal plasma AVP significantly increased $(0.9 \pm 0.2$ to 5.4 $\left.\pm 1.4 \mathrm{pg} / \mathrm{mL}, F_{18,4}=8.7, p<0.01\right)$ at $60 \mathrm{~min}$ after infusion of hypertonic $\mathrm{NaCl}$, in association with a 2 to $3 \%$ increase of maternal plasma osmolality. Fetal plasma AVP did not change at $60 \mathrm{~min}$ of $\mathrm{NaCl}$ infusion $(0.9 \pm 0.1$ to $1.8 \pm 0.5 \mathrm{pg} / \mathrm{mL}, \mathrm{NS})$, despite an approximately $5 \%$ increase of fetal plasma osmolality.

ECoG and swallowing EMG activity. There was no difference in the percentage of LV ECoG between control and treated groups $\left(F_{8,1}=0.47, \mathrm{NS}\right)$. For animals infused with hypertonic saline, percent time in fetal LV ECoG (50.4 \pm $7.7 \%$ ) did not change in response to infusions of $0.85 \mathrm{M}$ or 4 $\mathrm{M}$ hypertonic $\mathrm{NaCl}\left(F_{13,2}=0.04, \mathrm{NS}\right.$; Fig. 1$)$. For the control animals, no significant difference for LV ECoG was observed before and after i.v. infusion of $0.15 \mathrm{M} \mathrm{NaCl}$ (Fig. 1). However, fetal swallowing responses were significantly different between control and treated fetal ovines $\left(F_{8,1}=12.3, p=\right.$ $0.01)$. In the experimental animals, baseline fetal swallowing $(0.84 \pm 0.1$ swallows/LV ECoG) did not change significantly in response to i.v. $0.85 \mathrm{M} \mathrm{NaCl}$, but increased 3-fold (2.62 \pm $0.49)$ after the infusion of $4 \mathrm{M} \mathrm{NaCl}\left(F_{13,2}=9.68, p<0.01\right.$; Fig. 2). There was no change in swallowing activity during the control study.

FOS-ir. There was little FOS-ir in the forebrain structures among the control fetuses. Intravenous hypertonic saline produced intense FOS-ir in the fetal basal forebrain. The areas of strongest FOS-ir staining included the OVLT and MnPO. There were significant differences of FOS-ir between control and hypertonic $\mathrm{NaCl}$-infused fetuses (OVLT, $t=12.1$; ventral $\mathrm{MnPO}, t=7.09$; dorsal MnPO, $t=6.06$, all $p<0.01$; Figs. 3 and 4). FOS-ir was distributed throughout the OVLT and the MnPO. FOS-ir also was increased in the SFO in hypertonic compared with isotonic treated fetuses $(t=2.96, p<0.05)$. In the hypothalamus, FOS-ir was increased after infusion of hypertonic saline in the SON and PVN.

In the hindbrain, no or very little FOS-ir was observed in the LPBN, AP, and NTS in isotonic saline-treated fetuses. However, hypertonic saline fetuses demonstrated significantly increased FOS- ir in the LPBN $(t=7.45, p<0.01)$ AP $(t=$ $4.36, p<0.01)$, and rostral and caudal NTS ( $t=6.46$ and 2.83, $p<0.01$ and 0.05 , respectively). FOS-ir was also observed in the commissural NTS in the fetuses infused with hypertonic saline (Fig. 5).

\section{DISCUSSION}

The results of the present study indicate that near-term fetal swallowing can be stimulated only by relatively higher plasma hypertonicity than that required by adult animals. Furthermore,

Table 1. Fetal arterial values before and after intravenous $0.15 \mathrm{M} \mathrm{NaCl}$ infusion

\begin{tabular}{|c|c|c|c|c|c|}
\hline & Baseline & $15 \mathrm{~min}$ & $30 \mathrm{~min}$ & $60 \mathrm{~min}$ & $100 \mathrm{~min}$ \\
\hline Het $(\%)$ & $31.0 \pm 1.9$ & $31.7 \pm 2.1$ & $31.5 \pm 2.0$ & $31.6 \pm 2.2$ & $31.2 \pm 1.8$ \\
\hline $\mathrm{Hb}(\mathrm{g} / \mathrm{dL})$ & $9.8 \pm 0.8$ & $10.0 \pm 0.5$ & $9.7 \pm 0.6$ & $9.8 \pm 0.4$ & $9.7 \pm 0.6$ \\
\hline $\mathrm{pH}$ & $7.37 \pm 0.01$ & $7.36 \pm 0.02$ & $7.37 \pm 0.02$ & $7.37 \pm 0.01$ & $7.37 \pm 0.01$ \\
\hline $\mathrm{PcO} 2(\mathrm{~mm} \mathrm{Hg})$ & $50.5 \pm 4.4$ & $50.1 \pm 4.6$ & $50.0 \pm 1.9$ & $50.2 \pm 3.4$ & $49.2 \pm 2.3$ \\
\hline Osmolality (mosmol/kg) & $298 \pm 4$ & $296 \pm 4$ & $296 \pm 4$ & $294 \pm 5$ & $296 \pm 4$ \\
\hline $\mathrm{Na}(\mathrm{mEq} / \mathrm{L})$ & $141 \pm 2$ & $140 \pm 2$ & $140 \pm 2$ & $139 \pm 2$ & $142 \pm 4$ \\
\hline
\end{tabular}


Table 2. Maternal arterial values before and after intravenous $0.15 \mathrm{M} \mathrm{NaCl}$ infusion

\begin{tabular}{|c|c|c|c|c|c|}
\hline & Baseline & $15 \mathrm{~min}$ & $30 \mathrm{~min}$ & $60 \mathrm{~min}$ & $100 \mathrm{~min}$ \\
\hline Hct $(\%)$ & $28.2 \pm 1.9$ & $29 \pm 3.4$ & $28 \pm 2.1$ & $28 \pm 2.3$ & $27 \pm 2.5$ \\
\hline $\mathrm{pH}$ & $7.44 \pm 0.01$ & $7.42 \pm 0.02$ & $7.45 \pm 0.02$ & $7.44 \pm 0.01$ & $7.44 \pm 0.02$ \\
\hline $\mathrm{Po}_{2}(\mathrm{~mm} \mathrm{Hg})$ & $114 \pm 6$ & $96 \pm 12$ & $118 \pm 3$ & $116 \pm 6$ & $114 \pm 4$ \\
\hline Osmolality (mosmol/kg) & $301 \pm 1$ & $301 \pm 4$ & $301 \pm 4$ & $300 \pm 3$ & $299 \pm 2$ \\
\hline $\mathrm{Na}(\mathrm{mEq} / \mathrm{L})$ & $145 \pm 1$ & $144 \pm 2$ & $146 \pm 1$ & $146 \pm 1$ & $144 \pm 2$ \\
\hline $\mathrm{K}(\mathrm{mEq} / \mathrm{L})$ & $4 \pm 0$ & $4.1 \pm 0$ & $4 \pm 0$ & $4 \pm 0$ & $3.9 \pm 1$ \\
\hline
\end{tabular}

Table 3. Fetal arterial values before and after intravenous $0.85 \mathrm{M}$ followed by $4 \mathrm{M} \mathrm{NaCl}$ infusion

\begin{tabular}{|c|c|c|c|c|c|}
\hline & Baseline & $15 \mathrm{~min}$ & $30 \mathrm{~min}$ & $60 \mathrm{~min}$ & $100 \mathrm{~min}$ \\
\hline Hct $(\%)$ & $30 \pm 1$ & $29 \pm 2$ & $28 \pm 3$ & $29 \pm 2$ & $28 \pm 1$ \\
\hline $\mathrm{Hb}(\mathrm{g} / \mathrm{dL})$ & $8.8 \pm 1.7$ & $8.8 \pm 2.0$ & $9.1 \pm 1.1$ & $9.1 \pm 1.5$ & $9.0 \pm 1.2$ \\
\hline $\mathrm{pH}$ & $7.36 \pm 0.01$ & $7.39 \pm 0.1$ & $7.34 \pm 0.02$ & $7.33 \pm 0.01$ & $7.34 \pm 0.03$ \\
\hline $\mathrm{PCO}_{2}(\mathrm{~mm} \mathrm{Hg})$ & $52 \pm 2$ & $60 \pm 18$ & $51 \pm 2$ & $52 \pm 1$ & $50 \pm 9$ \\
\hline Osmolality (mosmol/kg) & $300 \pm 2$ & $305 \pm 1$ & $311 \pm 2$ & $318 \pm 7^{*}$ & $334 \pm 4^{*}$ \\
\hline $\mathrm{Na}(\mathrm{mEq} / \mathrm{L})$ & $141 \pm 1$ & $146 \pm 1$ & $147 \pm 1$ & $151 \pm 4^{*}$ & $163 \pm 2 *$ \\
\hline
\end{tabular}

Table 4. Maternal arterial values before and after intravenous $0.85 \mathrm{M}$ followed by $4 \mathrm{M} \mathrm{NaCl}$ infusion

\begin{tabular}{|c|c|c|c|c|c|}
\hline & Baseline & $15 \mathrm{~min}$ & $30 \mathrm{~min}$ & $60 \mathrm{~min}$ & $100 \mathrm{~min}$ \\
\hline Hct $(\%)$ & $27 \pm 3$ & $26 \pm 2$ & $25 \pm 2$ & $24 \pm 2$ & $25 \pm 2$ \\
\hline $\mathrm{pH}$ & $7.44 \pm 0.01$ & $7.4 \pm 0.02$ & $7.42 \pm 0.03$ & $7.41 \pm 0.02$ & $7.43 \pm 0.02$ \\
\hline $\mathrm{Po}_{2}(\mathrm{~mm} \mathrm{Hg})$ & $115 \pm 11$ & $117 \pm 9$ & $116 \pm 11$ & $112 \pm 7$ & $117 \pm 12$ \\
\hline Osmolality (mosmol/kg) & $303 \pm 6$ & $305 \pm 4$ & $309 \pm 7$ & $312 \pm 3^{*}$ & $319 \pm 7 *$ \\
\hline $\mathrm{Na}(\mathrm{mEq} / \mathrm{L})$ & $146 \pm 1$ & $148 \pm 1$ & $150 \pm 1$ & $151 \pm 2 *$ & $155 \pm 2 *$ \\
\hline $\mathrm{K}(\mathrm{mEq} / \mathrm{L})$ & $4.4 \pm 0.4$ & $4.7 \pm 1.2$ & $4.5 \pm 1.1$ & $4 \pm 0.3$ & $4.3 \pm 0.9$ \\
\hline
\end{tabular}

Table 5. Fetal cardiovascular responses before and after intravenous $0.85 \mathrm{M}$ followed by $4 \mathrm{M} \mathrm{NaCl}$ infusion

\begin{tabular}{|c|c|c|c|c|c|}
\hline & Baseline & $15 \mathrm{~min}$ & $30 \mathrm{~min}$ & $60 \mathrm{~min}$ & $100 \mathrm{~min}$ \\
\hline Systolic pressure (mm Hg) & $66 \pm 5$ & $68 \pm 4$ & $66 \pm 2$ & $64 \pm 2$ & $72 \pm 3$ \\
\hline Diastolic pressure (mm Hg) & $45 \pm 4$ & $46 \pm 2$ & $44 \pm 2$ & $44 \pm 3$ & $46 \pm 2$ \\
\hline MAP (mm Hg) & $56 \pm 4$ & $57 \pm 3$ & $55 \pm 2$ & $54 \pm 1$ & $59 \pm 2$ \\
\hline Adjusted MAP (mm Hg) & $46 \pm 3$ & $47 \pm 2$ & $46 \pm 0$ & $46 \pm 1$ & $49 \pm 2$ \\
\hline Heart rate (beats/min) & $162 \pm 17$ & $168 \pm 10$ & $170 \pm 10$ & $173 \pm 17$ & $171 \pm 7$ \\
\hline
\end{tabular}

MAP, mean arterial pressure.

despite the higher threshold requirements, cellular activation in response to osmotic stimulation occurs in both fetal forebrain and hindbrain structures.

Previous studies in adult animals have confirmed the importance of the anterior third ventricle region for detecting plasma hyperosmolality and mediating compensatory thirst and AVP secretion (20-23). As noted above, only a 2 to $3 \%$ increase in plasma osmolality is required to induce water intake in multiple adult species $(24,25)$, including sheep and humans $(26$, 27). In the present study, infusion of $0.85 \mathrm{M}$ hypertonic $\mathrm{NaCl}$ increased both maternal and fetal plasma osmolality. Extrapolating from time 0 to $60 \mathrm{~min}$, the average fetal osmolality during this period was approximately $310 \mathrm{mosmol} / \mathrm{kg}$. Despite this average $3 \%$ increase, there was no effect on fetal swallowing activity. These results are consistent with our previous studies suggesting that either short- or long-term $10 \mathrm{mosmol} / \mathrm{kg}$ plasma osmolality increases do not alter fetal swallowing $(1,5$, 28). However, plasma osmolality increases of approximately
$30 \mathrm{mosmol} / \mathrm{kg}$, or approximately $10 \%$ of basal values, resulted in a 3-fold increase in fetal swallowing activity. As the percentage of LV ECoG activity did not change in response to hypertonic saline infusion, the effects of plasma hypertonicity were independent of fetal neurobehavioral effects. These results suggest that the threshold for systemic osmotic stimulation in the ovine fetus at $90 \%$ gestation is relatively higher than that for mature animals, and the osmoregulation mechanisms in the ovine fetus near-term are either incompletely developed, or inhibited in utero.

Osmotic dipsogenic and AVP secretory responses may be modified by intravascular volume alterations. In preliminary studies (data not shown), we noted that fetal i.v. hypertonic saline infusions resulted in a marked decrease in fetal Hct, likely evidence of fetal plasma volume expansion resulting, in part, from increased maternal to fetal water flow in response to the altered transplacental osmotic gradient (29). So as not to obtund the fetal dipsogenic response with plasma volume 


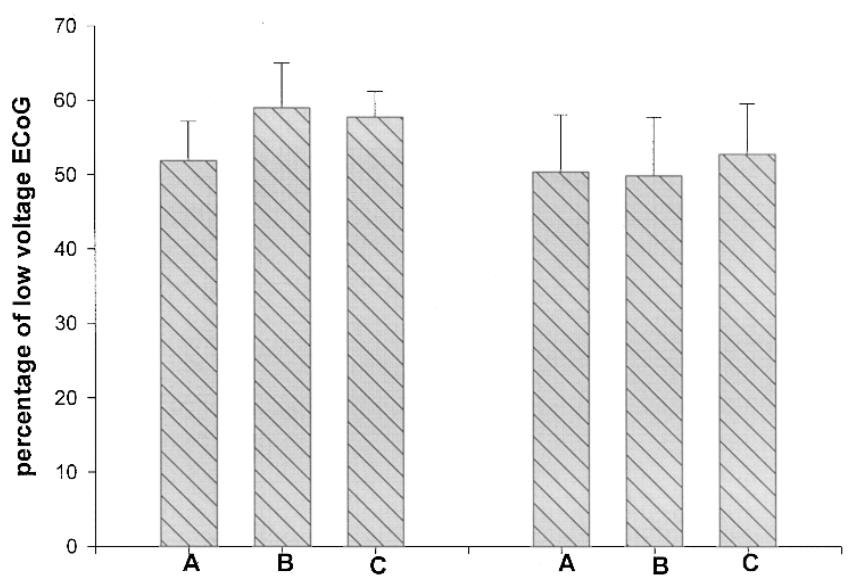

Fig. 1. Percentage time of fetal $\mathrm{LV}$ ECoG before and after i.v. $\mathrm{NaCl}$ infusion. Left three bars represent control fetuses during the baseline period $\mathrm{A}$, infusion period $\mathrm{B}(0.15 \mathrm{M} \mathrm{NaCl}, 0$ to $60 \mathrm{~min})$, and during and after infusion period $\mathrm{C}$ $(0.15 \mathrm{M} \mathrm{NaCl}, 60$ to $160 \mathrm{~min})$. Right three bars represent experimental fetuses during the baseline period $\mathrm{A}$, infusion period $\mathrm{B}(0.85 \mathrm{M} \mathrm{NaCl}, 0$ to $60 \mathrm{~min})$, and during and after infusion period $\mathrm{C}(4 \mathrm{M} \mathrm{NaCl}, 60$ to $160 \mathrm{~min})$.

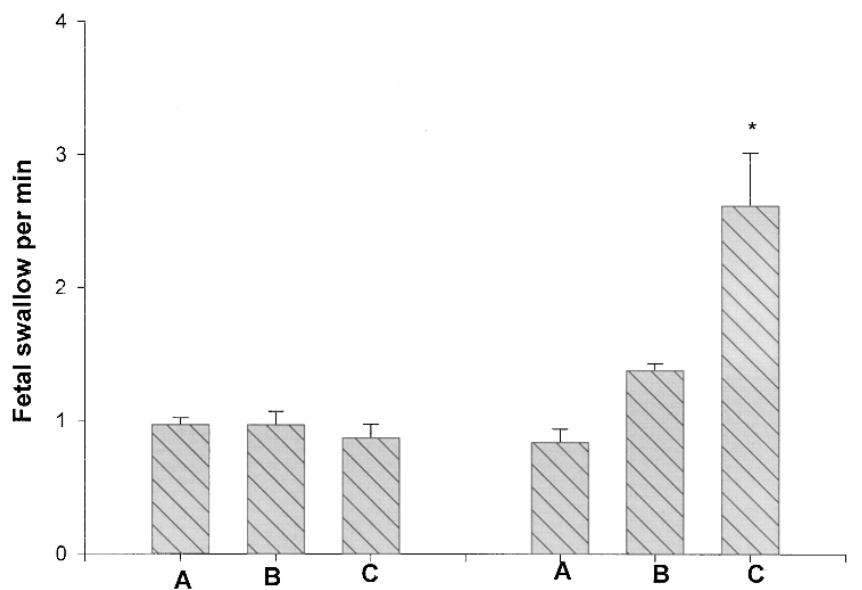

Fig. 2. Fetal swallowing activity before and after i.v. $\mathrm{NaCl}$ infusion. Left three bars represent control fetuses during the baseline period $\mathrm{A}$, infusion period $\mathrm{B}$ $(0.15 \mathrm{M} \mathrm{NaCl}, 0$ to $60 \mathrm{~min})$, and during and after infusion period $\mathrm{C}(0.15 \mathrm{M}$ $\mathrm{NaCl}, 60$ to $160 \mathrm{~min}$ ). Right three bars represent experimental fetuses during the baseline period $\mathrm{A}$, infusion period $\mathrm{B}(0.85 \mathrm{M} \mathrm{NaCl}, 0$ to $60 \mathrm{~min})$, and during and after infusion period $\mathrm{C}(4 \mathrm{M} \mathrm{NaCl}, 60$ to $160 \mathrm{~min})$. $* p<0.05 v \mathrm{~s}$ baseline.

expansion, the present study design included simultaneous hypertonic saline infusions to the maternal ewe and fetus. Although fetal plasma osmolality increased to a greater degree, the increased maternal plasma osmolality markedly reduced the effective placental osmotic gradient. Although fetal interstitial to intravascular water flow also may occur in response to plasma hypertonicity, fetal Hct decreased only minimally during the hypertonic infusions. The nonsignificant trend toward reduced Hct may be a reflection of red blood cell shrinkage in response to plasma hypertonicity. Fetal $\mathrm{Hb}$ did not change during the hypertonic infusions, suggesting that fetal plasma volume remained relatively unchanged during the study, probably because of the duel maternal and fetal infusions. In recognition of the stable fetal arterial blood pressure and heart rate, and the aforementioned $\mathrm{Hb}$ levels, these results suggest that intravascular volume changes and volume-related barore-

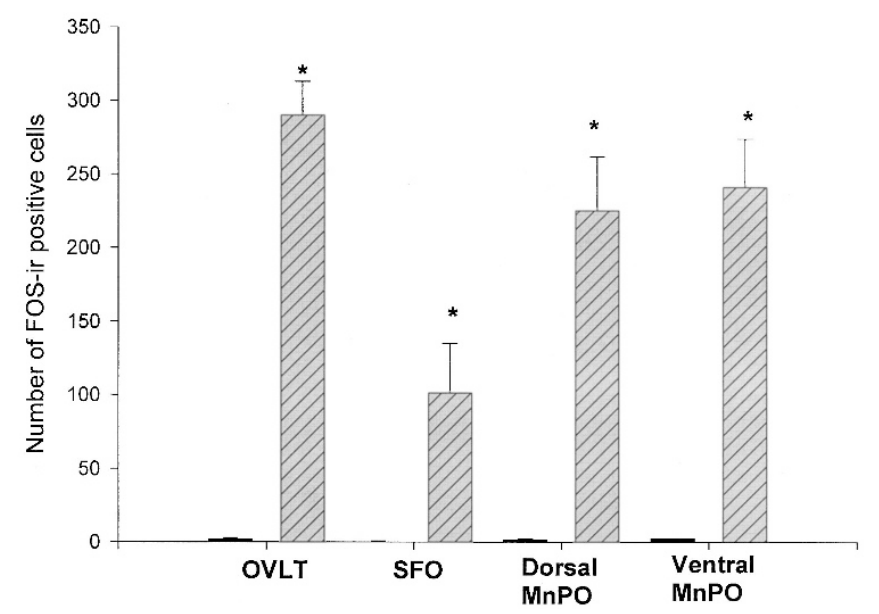

Fig. 3. Effects of i.v. $\mathrm{NaCl}$ on FOS-ir induced in the fetal lamina terminalis. Solid bars represent control fetuses (isotonic $\mathrm{NaCl}$, i.v.); hatched bars represent experimental fetuses (hypertonic $\mathrm{NaCl}$, i.v.). ${ }^{*}: p<0.05 v s$ control.

flex effects on dipsogenic response and neuron activity in the fetal brain were very limited. Thus, fetal dipsogenic and cellular responses were likely a reflection of primary osmotic effects.

Previous studies have suggested that plasma hypertonicity induces FOS-ir in the forebrain of the near-term ovine fetus (12). However, in one study (7) fetal plasma composition changes were not quantified, and maternal mannitol-induced plasma hypertonicity may have induced fetal plasma volume contraction, contributing to central dipsogenic stimulation. In a subsequent study (12), pain or stress from intraperitoneal fetal hypertonic injections may have induced central c-fos expression $(13,14)$. Notably, neither of the previous studies simultaneously confirmed fetal swallowing activity in relation to c-fos expression. To avoid potential nonspecific c-fos stimulation, the present study infused hypertonic saline i.v. into the fetus. The cellular activity marked by FOS-ir in putative central osmoreceptor areas (OVLT, MnPO, and SFO) $(10,30)$ and the demonstration of stimulated swallowing activity are evidence that central integrative areas for dipsogenic mechanisms were excited by i.v. hypertonic saline.

It is noted that c-fos expression requires a period up to 30 min after a given stimuli. As neural responses are within a time base of milliseconds to seconds with subsequent fast modulation of swallowing behavior, the FOS-ir results in the present study do not suggest a functional relation in time course between c-fos expression and fetal swallow. However, neural activation labeled by FOS-ir in the dipsogenic nuclei indicates that osmosensitive centers were activated under stimulation of hypertonicity.

In addition to the quantitative analysis of FOS-ir, the distribution pattern of FOS-ir within the activated cells of the anterior third ventricle region was notable. Excited cells in the MnPO showed a widespread pattern of FOS-ir distribution within the nuclei, similar to that observed in adult animals $(9-11)$. However, the fetal OVLT also demonstrated a widespread distribution pattern throughout the nuclei, whereas previous studies of adult rats indicate OVLT c-fos expression primarily localized to the dorsal part of this area, in response to 

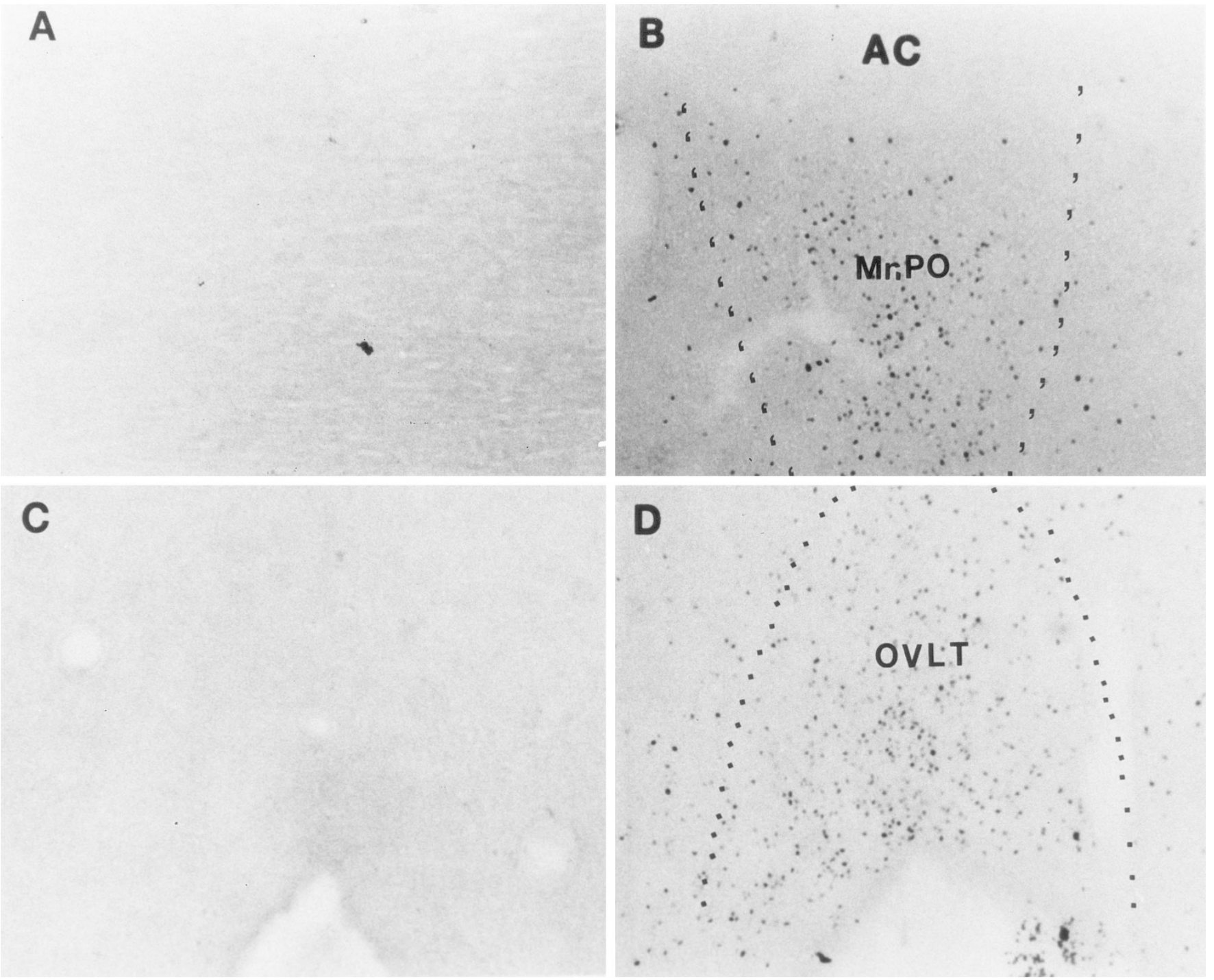

Fig. 4. Effects of i.v. hypertonic $\mathrm{NaCl}$ on FOS-ir in the forebrain. $A$ and $B, \mathrm{MnPO} ; C$ and $D$, OVLT. $A$ and $C$, i.v. isotonic $\mathrm{NaCl} ; B$ and $D$, i.v. hypertonic NaCl. $A C$, anterior commissure. Magnification $\times 20$.

hypertonicity $(10,23)$. The diffuse OVLT ovine fetal response is consistent with our recent finding in the near-term rat fetal brain (31). These regional differences in cellular activity between the fetus and adult may suggest the possibility of species differences between sheep or rat or that fetal OVLT osmoreceptors have not completely finished their development, with osmosensitive components either losing osmotic responsiveness or, perhaps less likely, migrating to other regions later. However, the absence of fetal swallowing stimulation and the previously demonstrated lack of fetal AVP response at plasma osmolality increases of approximately $5 \%$ by hypertonic saline infusion (31) may suggest a downstream neural and synaptic immaturity in fetal sheep.

In the present study, we also examined the fetal hindbrain under condition of hypertonicity. Although the precise function of the hindbrain in control of dipsogenic behavior is not clear, systemic hyperosmolality induces c-fos expression in the adult AP, NTS, and LPBN (32), suggesting a role in the control of body fluid homeostasis. In rats, lesions of the AP and the adjacent caudal NTS, or destruction of bilateral LPBN, to which the AP and NTS have substantial secondary projections, results in large increases in water and salt intake in response to angiotensin II, compared with control animals (25, 33-35). From these observations, it has been hypothesized that APNTS-LBPN systems comprise inhibitory mechanisms for dipsogenic responses. However, drinking was not altered in AP, NTS, or LPBN lesioned rats by systemic hypertonic saline (33, $34)$. Induced c-fos expression in the NTS by systemic hyperosmolality is correlated with vagally mediated gastric emptying (36). Thus, the NTS has been suggested to play a role in taste and visceral sensory information. Hindbrain activation also may be related to cardiovascular responses as adult baroreflex cardiovascular activity may induce cellular activation and c-fos expression in the NTS and LPBN. As systemic administration of hypertonic saline may change blood pressure, heart rate, and circulation volume (37-39), it remains uncertain whether hindbrain responses are secondary to dipsogenic or cardiovascular responses. In the present study, fetal systolic, diastolic, and mean arterial pressure and heart rate did not change significantly. Thus, it is unlikely that NTS activation 


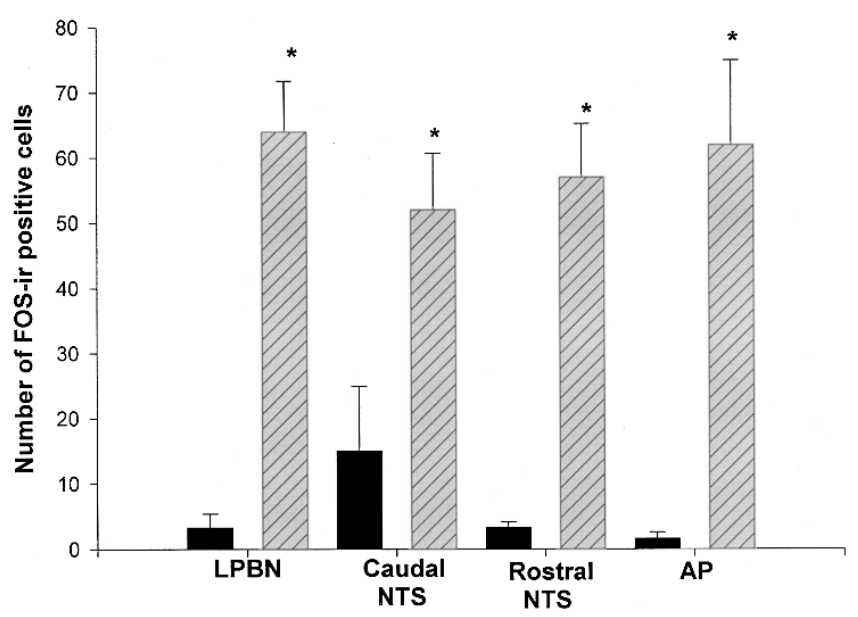

Fig. 5. Effects of i.v. $\mathrm{NaCl}$ on FOS-ir induced in the fetal hindbrain. Solid bars represent control fetuses (isotonic $\mathrm{NaCl}$, i.v.); Hatched bars represent experimental fetuses (hypertonic $\mathrm{NaCl}$, i.v.). $*: p<0.05$ vs control.

was mediated by a fetal arterial baroreceptor reflex. Rinaman et al. (19) recently reported that s.c. hypertonic $\mathrm{NaCl}$ induced a similar pattern of c-fos expression in the forebrain of adult and 2-d-old neonatal rats. However, adult, although not neonatal, rats expressed FOS-ir in the AP, the LPBN, and the medial NTS (19). The present study demonstrated significant FOS induction in the ovine fetal hindbrain. Differences in species and levels of hypertonicity may explain the paradox between the present findings and previous results (19). To our knowledge, this is the first study demonstrating hypertonicity not only induces c-fos expression in the forebrain, but also in the LPBN, AP, and NTS of the fetal hindbrain. However, without quantitative and detailed analysis on both adult and fetal animals under the same experimental condition, we cannot conclude that the fetal hindbrain sensitivity and c-fos responses are identical to those of adults. Nevertheless, these results indicate that the near-term ovine fetal hindbrain is able to respond to osmotic stimulation.

In conclusion, this study demonstrates that higher levels of systemic hypertonicity ( $>2$ to $3 \%$ change of plasma osmolality) are required to evoke near-term fetal swallowing. The behavioral response is specific to dipsogenic mechanisms as confirmed by c-fos expression in dipsogenic neural centers including the OVLT and MnPO. Fetal behavioral and cellular responses to intracellular dehydration suggest that the mechanisms for control of body fluid regulation at 0.9 ovine gestation has developed to a relatively intact, but not completely mature, stage. In addition, this study is the first to demonstrate that i.v. hypertonicity, without the influence of stress or cardiovascular alterations, can induce c-fos expression in the hindbrain AP, NTS, and LPBN. Together, this study provides evidence that osmoregulatory mechanisms function in the near-term ovine fetus.

Acknowledgments. The authors thank the following people for their technical help and assistance. Linda Day, Jim Humme and Dr. Jeong Jae Lee assisted in sheep surgery and physiological studies, and Jiaming Yao aided in brain tissue sectioning and immunocytochemisty procedure.

\section{REFERENCES}

1. Ross M, Agnew C, Fujino Y, Ervin M, Day L 1992 Concentration thresholds for fetal swallowing and vasopressin secretion. Am J Physiol 262:R1057-R1063

2. Ross MG, Kullama LK, Ogundipe OA, Chan K, Ervin M G 1995 Ovine fetal swallowing response to intracerebroventricular hypertonic saline. J Appl Physiol 78:2267-2271

3. Ross MG, Nijland MJM, Kullama LK, Day L 1995 Reset osmotic thresholds for stimulation of ovine fetal swallowing. J Soc Gynecol Invest 2:327 (abstr)

4. Ross MG, Sherman DJ, Ervin MG, Day L, Humme J 1989 Stimuli for fetal swallowing: systemic factors. Am J Obstet Gynecol 161:1559-1565

5. Ross MG, Sherman DJ, Schreyer P, Ervin MG, Day L, Humme JA 1991 Fetal rehydration via intraamniotic fluid: contribution of fetal swallowing. Pediatr Res 29:214-217

6. Hamamura M, Nunez D, Leng G, Emson P, Kiyama H 1992 c-fos may code for a common transcription factor within the hypothalamic neural circuits involved in osmoregulation. Brain Res 572:42-51

7. McDonald TJ, Li C, Nijland MJ, Caston-Balderrama A, Ross MG 1988 Fos response of fetal sheep anterior circumventricular organs to osmotic challenge in late gestation. Am J Physiol 275:H609-H614

8. Leng G, Blackburn R, Dyball RE, Russell J 1989 Role of anterior peri-third ventricular structures in the regulation of supraoptic neuronal activity and neurohypophysial hormone secretion in the rat. J Neuroendocrinol 1:35-46

9. McKinley M, Hards D, Oldfield B 1994 Identification of neural pathways activated in dehydrated rats by means of Fos-immunohistochemistry and neural tracing. Brain Res 653:305-314

10. Oldfield B, Badoer E, Hards D, McKinley M 1994 Fos production in retrogradely labeled neurons of the lamina terminalis following intravenous infusion of either hypertonic saline or angiotensin II. Neuroscience 60:255-262

11. Xu Z, Herbert J 1995 Regional suppression by lesions in the anterior third ventricle of c-fos expression induced by either angiotensin II or hypertonic saline. Neuroscience 67:135-147

12. Caston-Balderrama A, Nijland MJM, McDonald TJ, Ross MG 1999 Central Fos expression in fetal and adult sheep following intraperitoneal hypertonic saline. Am J Physiol 276:H725-H735

13. Patronas P, Horowitz M, Simon E, Gerstberger R 1998 Differential stimulation of c-fos expression in hypothalamic nuclei of the rat brain during short-term heat acclimation and mild dehydration. Brain Res 798:127-139

14. Sharp FR, Sagar SM, Hicks K, Lowenstein D, Hisanaga K 1991 c-fos mRNA, Fos, and Fos-related antigen induction by hypertonic saline and stress. J Neurosci 11:2321-2331

15. Kullama LK, Agnew CL, Day L, Ervin MG, Ross MG 1994 Ovine fetal swallowing and renal responses to oligohydramnios. Am J Physiol 266:R972-R978

16. Ross MG, Kullama LK, Ogundipe OA, Chan K, Ervin MG 1994 Central angiotensin II stimulation of ovine fetal swallowing. J Appl Physiol 76:1340-1345

17. Sherman DJ, Ross MG, Day L, Ervin MG 1990 Fetal swallowing: correlation of electromyography and esophageal fluid flow. Am J Physiol 258:R1386-R1394

18. Harding R, Sigger JN, Poore ER, Johnson P 1984 Ingestion in fetal sheep and its relation to sleep states and breathing movements. Q J Exp Physiol 69:477-486

19. Rinaman L, Stricker EM, Hoffman GE, Verbalis JG 1997 Central c-Fos expression in neonatal and adult rats after subcutaneous injection of hypertonic saline. Neuroscience 79:1165-1175

20. Johnson AK, Edward GL 1990 The neuroendocrinology of thirst: afferent signaling and mechanisms of central integration. In: Pfaff DW, Ganten D (eds) Current Topics in Neuroendocrinology. Springer-Verlag, Berlin, pp 149-190

21. Leng G, Dyball RE, Luckman SM 1992 Mechanisms of vasopressin secretion. Horm Res 37:33-38

22. Rundgren M, Denton D, McKinley M, Weisinger R 1986 The dipsogenic effect of intracerebroventricular infusion of hypertonic $\mathrm{NaCI}$ in the sheep is mediated mainly by the Na ion. Acta Physiol Scand 127:433-436

23. Xu Z, Herbert J 1996 Effects of unilateral or bilateral lesions within the anteroventral third ventricular region on c-fos expression induced by dehydration or angiotensin II in the supraoptic and paraventricular nuclei of the hypothalamus. Brain Res 713:36-43

24. Fitzsimons JT 1963 The effects of slow infusions of hypertonic solutions on drinking and drinking thresholds in rats. J Physiol (Lond) 167:344-354

25. Fitzsimons JT 1998 Angiotensin, thirst, and sodium appetite. Physiol Rev 78:583686

26. Gordon SG, Majzoub JA, Williams GH, Gordon MB 1997 Sodium balance modulates thirst in normal man. Endocr Res 23:377-392

27. Rundgren M, Jonasson H, Hjelmqvist H 1990 Water intake and changes in plasma and CSF composition in response to acute administration of hypertonic $\mathrm{NaCI}$ and water deprivation in sheep. Acta Physiol Scand 138:85-92

28. Agnew CL, Ross MG, Fujino Y, Ervin MG, Kullama LK 1992 Fetal renal and endocrine response to intravenous saline infusion during dehydration. J Soc Gynecol Invest 1:268 (abstr)

29. Leake RD, Hobel CJ, Okada DM, Ross MG Williams PR 1983 Neonatal metabolic effects of oral ritodrine hydrochloride administration. Pediat Pharm 3:101-106

30. McKinley M, Denton D, Weisinger R 1978 Sensors for antidiuresis and thirst: osmoreceptors or CSF sodium detectors? Brain Res 141:89-103

31. Xu Z, Glenda C, Day L, Yao J, Ross MG 2000 Osmotic threshold and sensitivity for vasopressin release and $\mathrm{Fos}$ expression by hypertonic $\mathrm{NaCl}$ in ovine fetus. $\mathrm{Am} \mathrm{J}$ Physiol 279: E1207-E1215

32. Xu Z, Herbert J 1994 Regional suppression by water intake of c-fos expression induced by intraventricular infusions of angiotensin II. Brain Res 659:157-168 
33. Edwards GL, Johnson AK 1991 Enhanced drinking after excitotoxic lesions of the parabrachial nucleus in the rat. Am J Physiol 261:R1039-R1044

34. Edwards GL, Ritter RC 1982 Area postrema lesions increase drinking to angiotensin and extracellular dehydration. Physiol Behav 29:943-947

35. Ohman LE, Johnson AK 1986 Lesions in lateral parabrachial nucleus enhance drinking to angiotensin II and isoproterenol. Am J Physiol 251:R504-R509

36. Olson BR, Freilino M, Hoffman GE, Stricker EM 1993 c-fos expression in rat brain and brainstem nuclei in response to treatments that alter food intake and gastric motility. Mol Cell Neurosci 4:93-106
37. Chan RKW, Sawchenko PE 1998 Organization and transmitter specificity of medullary neurons activated by sustained hypertension: implications for understanding baroreceptor reflex circuitry. J Neurosci 18:371-387

38. Dean C, Seagard JL 1995 Expression of c-Fos protein in the nucleus tractus solitarius in response to physiological activation of carotid baroreceptors. Neuroscience 69:249-257

39. Minson JB, Llewellyn-Smith IJ, Arnolda LF, Pilowsky PM, Chalmers JP 1997 c-fos expression in central neurons mediating the arterial baroreceptor reflex. Clin Exp Hypertens 19:631-643 